\title{
Recurrence of a small gastric gastrointestinal stromal tumor with high mitotic index
}

\author{
Jayanthi Vijayakumar, MBBS, ,a, Tetyana Mettler, MD, ${ }^{\mathrm{b}, \mathrm{c}}$ and Keith M Skubitz, MDª,b
}

${ }^{a}$ Department of Medicine, University of Minnesota Medical School; ${ }^{b}$ Department of Laboratory Medicine and Pathology, University of Minnesota Medical School; and 'Masonic Cancer Center, University of Minnesota Medical School, Minneapolis, Minnesota

$\mathrm{G}$ astrointestinal stromal tumor (GIST) is the most common soft tissue sarcoma of the gastrointestinal tract, usually arising from the interstitial cells of Cajal or similar cells in the outer wall of the gastrointestinal tract. ${ }^{1,2}$ Most GISTs have an activating mutation in KIT or platelet-derived growth factor receptor alpha (PDGFRA). Tumor size, mitotic rate, and anatomic site are the most common pathological features used to risk stratify GIST tumors. ${ }^{3-10}$ It is important to note when using such risk calculators that preoperative imatinib before determining tumor characteristics (such as mitoses per 50 high-power fields [hpf]) often changes the relevant parameters so that the same risk calculations may not apply. Tumors with a mitotic rate $\leq 5$ mitoses per $50 \mathrm{hpf}$ and a size $\leq 5$ $\mathrm{cm}$ in greatest dimension have a lower recurrence rate after resection than tumors with a mitotic rate $>5$ mitoses per $50 \mathrm{hpf}$ and a size $>10 \mathrm{~cm}$, and larger tumors can have a recurrence rate of up to $86 \% .^{11,12}$ Findings from a large observational study have suggested that the prognosis of gastric GIST in Korea and Japan may be more favorable compared with that in Western countries. ${ }^{13}$

The primary treatment of a localized primary GIST is surgical excision, but a cure is limited by recurrence. ${ }^{14,15}$ Imatinib is useful in the treatment of metastatic or recurrent GIST, and adjuvant treatment with imatinib after surgery has been shown to improve progression-free and overall survival in some cases. ${ }^{3,16-18}$ Responses to adjuvant imatinib depend on tumor sensitivity to the drug and the risk of recurrence. Drug sensitivity is largely dependent on the presence of mutations in KIT or PDGFRA. ${ }^{3,18}$ Recurrence risk is highly dependent on tumor size, tumor site, tumor rupture, and mitotic index. ${ }^{1,3,5,6,8,9,18,19}$ Findings on the use of gene expression patterns to predict recurrence risk have also been reported. ${ }^{20-27}$ However, recurrence risk is poorly understood for categories in which there are few cases with known outcomes, such as very small gastric GIST with a high mitotic index. For example, few cases of gastric GIST have been reported with a tumor size $\leq 2 \mathrm{~cm}$, a mitotic rate $>5$ mitoses per 50 hpf, and adequate clinical follow-up. In such cases, it is difficult to assess the risk of recurrence. ${ }^{6}$ We report here the long-term outcome of a patient with a $1.8 \mathrm{~cm}$ gastric GIST with a mitotic index of 36 mitoses per $50 \mathrm{hpf}$ and a KIT exon 11 mutation.

\section{Case presentation and summary}

A 69-year-old man presented with periumbilical and epigastric pain of 6-month duration. His medical history was notable for hyperlipidemia, hypertension, coronary angioplasty, and spinal surgery. $\mathrm{He}$ had a 40 pack-year smoking history and consumed 2 to 4 alcoholic drinks per day. The results of a physical examination were unremarkable. A computedtomographic (CT) scan showed no abnormalities. An esophagoduodenoscopy (EGD) revealed gastric ulcers. He was treated successfully with omeprazole $20 \mathrm{mg}$ by mouth daily.

A month later, a follow-up EGD revealed a 1.8 $\times 1.5 \mathrm{~cm}$ submucosal mass $3 \mathrm{~cm}$ from the gastroesophageal junction. The patient underwent a fundus wedge resection, and a submucosal mass 1.8 $\mathrm{cm}$ in greatest dimension was removed. Pathologic examination revealed a GIST, spindle cell type, with a mitotic rate of 36 mitoses per $50 \mathrm{hpf}$ with negative margins. Immunohistochemistry was positive for CD117. An exon 11 deletion (KVV558-560NV) was present in KIT. The patient's risk of recurrence

\footnotetext{
Accepted for publication April 10, 2018. Correspondence: Keith M Skubitz, MD; skubi001@umn.edu. Disclosures: The authors report no disclosures or conflicts of interest. JCSO 2018;16(3):e163-e166. (O2018 Frontline Medical Communications. doi: https://doi.org/10.12788/jcso.0402
} 

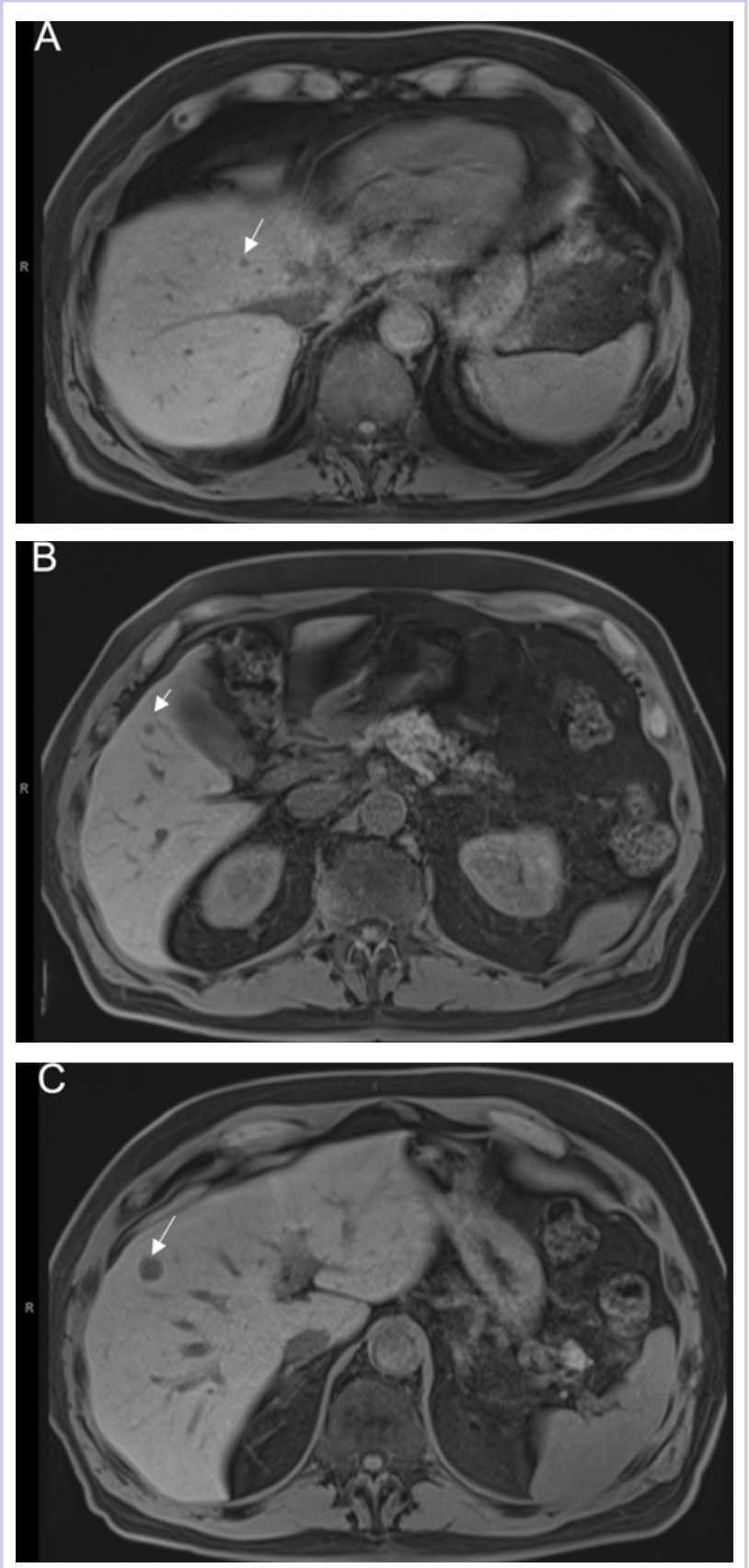

FIGURE 1 Magnetic resonance imaging of the liver demonstrating metastatic disease (arrows, $A$ and $B$ ), with a $1.2 \times 1.3-\mathrm{cm}$ mass in the hepatic segment $4 a / 8(C)$.

was unclear, and his follow-up included CT scans of the abdomen and pelvis every 3 to 4 months for the first 2 years, then every 6 months for the next 2.5 years.

A CT scan about 3.5 years after primary resection revealed small nonspecific liver hypodensities that became more prominent during the next year. About 5 years after primary resection, magnetic resonance imaging (MRI) revealed several liver lesions, the largest of which mea-
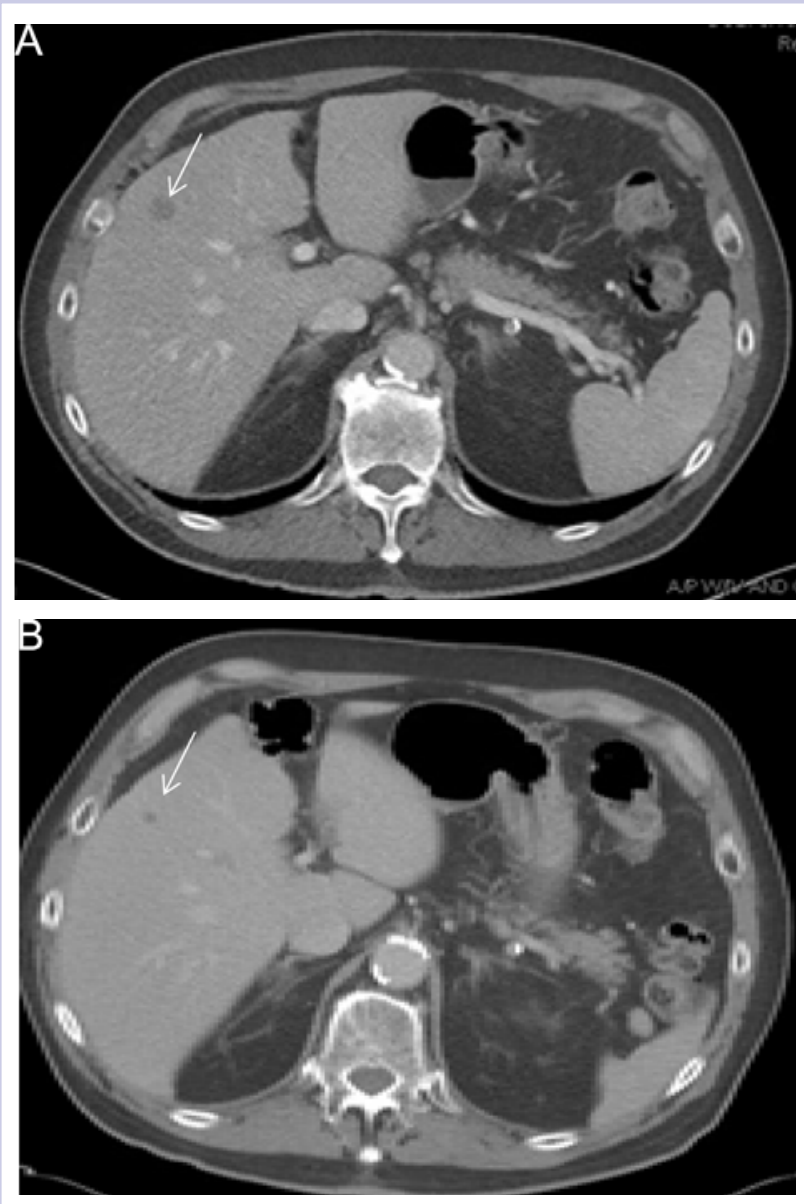

FIGURE 2 Computed-tomographic scan images of the abdomen and pelvis with contrast, before initiation of imatinib $(A)$ and 16 months after initiation of imatinib (B).

sured at $1.3 \mathrm{~cm}$ in greatest dimension. The patient's liver metastases were readily identified by MRI (Figure 1) and CT imaging (Figure 2A). Most GISTs are fluorodeoxyglucose (FDG) avid on positron-emission tomography (PET) imaging. In contrast, this patient's liver metastases had no detectable FDG uptake (not shown). A liver biopsy revealed recurrent GIST (Figure 3). Imatinib mesylate was begun at $400 \mathrm{mg}$ per day orally. After 2 months, the liver lesions were reduced in size, with the largest lesion shrinking to $0.5 \mathrm{~cm}$ in greatest dimension. The liver lesions continued to decrease in size and number (Figure 2B). At 16 months after starting imatinib, there was no sign of tumor progression.

\section{Discussion}

Small gastric GISTs are sometimes found by endoscopy performed for unrelated reasons. Recent data suggest that the incidence of gastric GIST may be higher than previously thought. In a Japanese study of patients with gastric cancer in which 100 stomachs were systematically exam- 


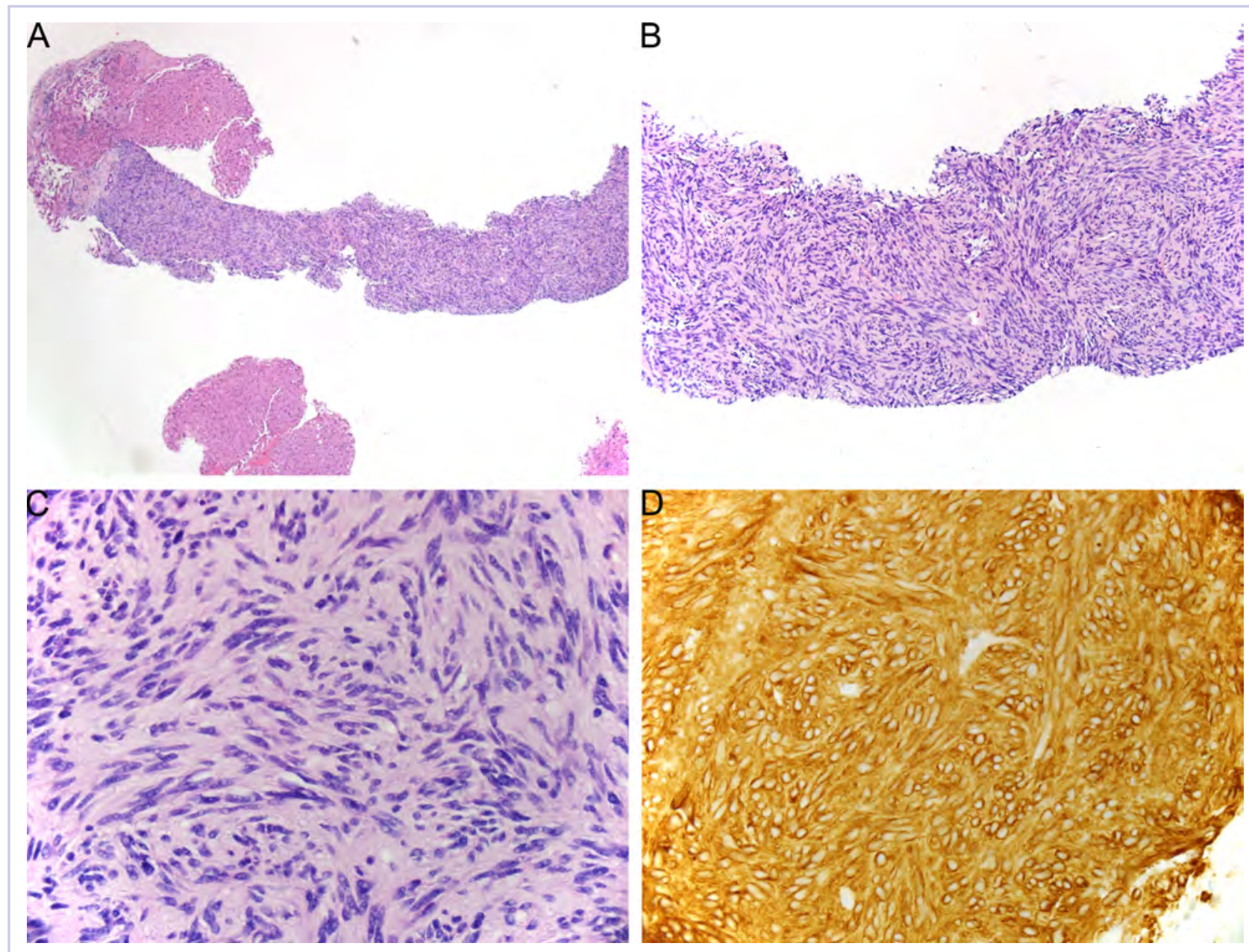

FIGURE 3 Histopathology of liver metastases showing (A) GIST (H\&E, x10); (B) spindle cell tumor arranged in intersecting tight fascicles $(H \& E, x 20) ;(C)$ metastatic GIST (H\&E stain, x40); and (D) strong CD 17 immunoreactivity in liver metastasis (x40).

ined pathologically, 50 microscopic GISTs were found in 35 patients. ${ }^{28}$ Most small gastric GISTs have a low mitotic index. Few cases have been described with a high mitotic index. In a study of 1765 cases of GIST of the stomach, 8 patients had a tumor size less than $2 \mathrm{~cm}$ and a mitotic index greater than 5 . Of those, only 6 patients had long-term follow-up, and 3 were alive without disease at 2,17 , and 20 years of follow-up. ${ }^{7}$ These limited data make it impossible to predict outcomes in patients with small gastric GIST with a high mitotic index.

For patients who are at high risk of recurrence after surgery, 3 years of adjuvant imatinib treatment compared with 1 year has been shown to improve overall survival and is the current standard of care. ${ }^{10,17} \mathrm{~A}$ study comparing 5 and 3 years of imatinib is ongoing to establish whether a longer period of adjuvant treatment is warranted. In patients with metastatic GIST, lifelong imatinib until lack of benefit is considered optimal treatment. ${ }^{10}$ All patients should undergo KIT mutation analysis. Those with the PDGFRA
D842V mutation, SDH (succinate dehydrogenase) deficiency, or neurofibromatosis-related GIST should not receive adjuvant imatinib.

This case has several unusual features. The small tumor size with a very high mitotic rate is rare. Such cases have not been reported in large numbers and have therefore not been reliably incorporated into risk prediction algorithms. In addition, despite a high mitotic index, the tumor was not FDG avid on PET imaging. The diagnosis of GIST is strongly supported by the KIT mutation and response to imatinib. This particular KIT mutation in larger GISTs is associated with aggressive disease. The present case adds to the data on the biology of small gastric GISTs with a high mitotic index and suggests the mitotic index in these tumors may be a more important predictor than size.

\section{Acknowledgment}

The authors thank Michael Franklin, MS, for editorial assistance, and Sabrina Porter for media edits. 


\section{References}

1. Corless CL, Barnett CM, Heinrich MC. Gastrointestinal stromal tumours: origin and molecular oncology. Nat Rev Cancer. 2011;11(12):865-878.

2. Hirota S, Isozaki K, Moriyama Y, et al. Gain-of-function mutations of c-kit in human gastrointestinal stromal tumors. Science. 1998;279(5350):577-580.

3. Corless CL, Ballman KV, Antonescu CR, et al. Pathologic and molecular features correlate with long-term outcome after adjuvant therapy of resected primary GI stromal tumor: the ACOSOG Z9001 trial. J Clin Oncol. 2014;32(15):1563-1570.

4. Huang J, Zheng DL, Qin FS, et al. Genetic and epigenetic silencing of SCARA 5 may contribute to human hepatocellular carcinoma by activating FAK signaling. J Clin Invest. 2010;120(1):223-241.

5. Joensuu H, Vehtari A, Riihimaki J, et al. Risk of recurrence of gastrointestinal stromal tumour after surgery: an analysis of pooled population-based cohorts. Lancet Oncol. 2012;13(3):265-274.

6. Miettinen M, Lasota J. Gastrointestinal stromal tumors: review on morphology, molecular pathology, prognosis, and differential diagnosis. Arch Pathol Lab Med. 2006;130(10):1466-1478.

7. Miettinen M, Sobin LH, Lasota J. Gastrointestinal stromal tumors of the stomach: a clinicopathologic, immunohistochemical, and molecular genetic study of 1765 cases with long-term follow-up. Am J Surg Pathol. 2005;29(1):52-68.

8. Patel S. Navigating risk stratification systems for the management of patients with GIST. Ann Surg Oncol. 2011;18(6):1698-1704.

9. Rossi S, Miceli R, Messerini L, et al. Natural history of imatinibnaive GISTs: a retrospective analysis of 929 cases with long-term follow-up and development of a survival nomogram based on mitotic index and size as continuous variables. Am J Surg Pathol. 2011;35(11):1646-1656.

10. National Comprehensive Cancer Network. Sarcoma. https://www. nccn.org. Accessed March 27, 2018.

11. Fletcher CD, Berman JJ, Corless C, et al. Diagnosis of gastrointestinal stromal tumors: a consensus approach. Int J Surg Pathol. 2002;10(2):81-89.

12. Huang HY, Li CF, Huang WW, et al. A modification of NIH consensus criteria to better distinguish the highly lethal subset of primary localized gastrointestinal stromal tumors: a subdivision of the original high-risk group on the basis of outcome. Surgery. 2007;141(6):748-756.

13. Kim MC, Yook JH, Yang HK, et al. Long-term surgical outcome of 1057 gastric GISTs according to 7 th UICC/AJCC TNM system: multicenter observational study From Korea and Japan. Medicine (Baltimore). 2015;94(41):e1526.

14. Casali PG, Blay JY; ESMO/CONTICANET/EUROBONET Consensus Panel of experts. Soft tissue sarcomas: ESMO Clinical
Practice Guidelines for diagnosis, treatment and follow-up. Ann Oncol. 2010;21(Suppl 5):v198-v203.

15. Joensuu H, DeMatteo RP. The management of gastrointestinal stromal tumors: a model for targeted and multidisciplinary therapy of malignancy. Annu Rev Med. 2012;63:247-258.

16. Dematteo RP, Ballman KV, Antonescu CR, et al. Adjuvant imatinib mesylate after resection of localised, primary gastrointestinal stromal tumour: a randomised, double-blind, placebo-controlled trial. Lancet. 2009;373(9669):1097-1104.

17. Joensuu H, Eriksson M, Sundby Hall K, et al. One vs three years of adjuvant imatinib for operable gastrointestinal stromal tumor: a randomized trial. JAMA. 2012;307(12):1265-1272.

18. Joensuu H, Rutkowski P, Nishida T, et al. KIT and PDGFRA mutations and the risk of GI stromal tumor recurrence. J Clin Oncol. 2015;33(6):634-642.

19. Fletcher CD, Berman JJ, Corless C, et al. Diagnosis of gastrointestinal stromal tumors: A consensus approach. Hum Pathol. 2002;33(5):459-465.

20. Antonescu CR, Viale A, Sarran L, et al. Gene expression in gastrointestinal stromal tumors is distinguished by KIT genotype and anatomic site. Clin Cancer Res. 2004;10(10):3282-3290.

21. Arne G, Kristiansson E, Nerman O, et al. Expression profiling of GIST: CD133 is associated with KIT exon 11 mutations, gastric location and poor prognosis. Int J Cancer. 2011;129(5):1149-1161.

22. Bertucci F, Finetti P, Ostrowski J, et al. Genomic Grade Index predicts postoperative clinical outcome of GIST. Br J Cancer. 2012;107(8):1433-1441.

23. Koon N, Schneider-Stock R, Sarlomo-Rikala M, et al. Molecular targets for tumour progression in gastrointestinal stromal tumours. Gut. 2004;53(2):235-240.

24. Lagarde P, Perot G, Kauffmann A, et al. Mitotic checkpoints and chromosome instability are strong predictors of clinical outcome in gastrointestinal stromal tumors. Clin Cancer Res. 2012;18(3):826-838.

25. Skubitz KM, Geschwind K, Xu WW, Koopmeiners JS, Skubitz AP. Gene expression identifies heterogeneity of metastatic behavior among gastrointestinal stromal tumors. J Transl Med. 2016;14:51.

26. Yamaguchi U, Nakayama R, Honda K, et al. Distinct gene expression-defined classes of gastrointestinal stromal tumor. J Clin Oncol. 2008;26(25):4100-4108.

27. Ylipaa A, Hunt KK, Yang J, et al. Integrative genomic characterization and a genomic staging system for gastrointestinal stromal tumors. Cancer. 2011;117(2):380-389.

28. Kawanowa K, Sakuma Y, Sakurai S, et al. High incidence of microscopic gastrointestinal stromal tumors in the stomach. Hum Pathol. 2006;37(12):1527-1535. 